\title{
CAUSATIVE AGENTS AND SUSCEPTIBILITY OF ANTIMICROBIALS AMONG SUSPECTED FEMALES WITH URINARY TRACT INFECTION IN TERTIARY CARE HOSPITALS OF WESTERN NEPAL
}

\author{
P Thapa \#, K Parajuli \#, A Poudel , A Thapa, B Manandhar, D Laudari, HB Malla , R Katiwada \\ School of Health and Allied Sciences, Pokhara University, Lekhnath, Kaski, Nepal. \\ \# Equal Contribution as First Author. \\ *Correspondence to : Ms Parbati Thapa, School of Health and Allied Sciences, Pokhara University, Lekhnath-12, Kaski, Nepal. \\ E-mail: parbatit@gmail.com
}

\begin{abstract}
Urinary Tract Infection (UTI) is a common and serious health problem affecting many people each year around the World especially females. Therapy of UTI relies on the predictability of the agents causing UTI and knowledge of their antimicrobial susceptibility patterns. A retrospective cross-sectional study was conducted in two major hospitals of Western Nepal. Tools for data collection were a data collection form. Total 400 patient's file with suspected UTI were reviewed, out of which $173(43.3 \%)$ of the suspected samples showed presence of potential pathogens causing UTI. UTI was mostly prevalent in females of age group 21-30. Escherichia coli (E. coli) was the predominant (65.1\%) bacterial pathogen. Amikacin was found to be most sensitive antimicrobial followed by Nitrofurantoin and Gentamcin. Ampicillin showed the higher percentage of resistant, compared to other antimicrobials. As drug resistance among bacterial pathogens is an evolving process, regular surveillance and monitoring is necessary to provide effective treatment of UTIs.
\end{abstract}

Key Words: UTI, Antimicrobials, Sensitivity \& Retrospective.

\section{INTRODUCTION}

Urinary Tract Infection (UTI) is defined as significant bacteriuria in the presence of symptoms. UTI is the most common bacterial infection, accounting for $25 \%$ of all infections. UTI can occur in any populations and age groups however, infection is most common in women in reproductive age. ${ }^{1}$ It is predicted that one half of all women will experience a UTI in their lifetime, and one in three women will receive antimicrobial therapy for UTI. ${ }^{2}$ UTI is a heterogeneous disease, which can be divided into several types of infections such as acute, uncomplicated bacterial pyelonephritis, complicated UTI, recurrent cystitis and asymptomatic bacteriuria. Acute UTI is one of the most common bacterial infections among women presenting to primary care. ${ }^{3}$ Symptomatic UTI are either uncomplicated or complicated. Uncomplicated infections occur in healthy women in the community and are usually caused by Escherichia coli (E. coli). Complicated infections are associated with anatomical, functional or metabolic abnormalities of the urinary tract that disable the natural innate host defense and lead to tissue injury. ${ }^{4}$ Major causative organisms for UTI are Escherichia coli, Klebsiella species, Proteus species, Pseudomonas species, Staphylococcus species. ${ }^{5}$

Bacterial UTIs are frequent infections in the outpatient as well as in the nosocomial setting. UTI is among the most prevalent microbial diseases and their financial burden on society is substantial. Approximately, 15\% of all community-prescribed antibiotics are dispensed for UTI. In uncomplicated UTIs, E. coli is the leading organism, whereas in complicated UTIs, the bacterial spectrum is much broad including Gram-negative and Gram-positive and often multi-resistant organisms. The therapy of uncomplicated UTIs is almost exclusively antibacterial, whereas in complicated UTIs the complicating factors have to be treated as well. There are two predominant aims in the antimicrobial treatment of both uncomplicated and complicated UTIs: (i) rapid and effective response to therapy and prevention of recurrence of the individual patient treated; (ii) prevention of emergence of resistance to antimicrobial chemotherapy in the microbial environment. ${ }^{6}$

\section{MATERIAL AND METHODS}

A retrospective cross-sectional study was conducted in two major hospitals of Western Nepal, Western Regional Hospital and Fishtail Hospital and Research Center in 2012, after approval of proposal from School of Health and Allied Sciences, Pokhara University, Lekhnath, Kaski, Nepal. Inclusion criteria for the study were the data of females patient suspected with UTI, data of sensitivity pattern that were upto five months back from time of study. Exclusion criteria were data of sensitivity 
pattern other than UTI, data of sensitivity pattern that was more than five months back from the time of study. Initially total 400 patient's files with suspected UTI were reviewed. Tools for data collection were the structured form and the variables for data collection were the patient's demographic data, the causative agent of the UTI and sensitivity and resistant pattern of antimicrobials. Results were analysed using SPSS version 17 for windows.

\section{RESULTS}

Age Distribution Among Suspected UTI Patients

Total 400 medical file were reviewed of patients suspected with UTI. Among those suspected with UTI a higher percentage of females $(27.8 \%)$ were found within the age group of 21-30 years, however the lowest percentage $(3.0 \%)$ of the patient were with age group greater than 80 years as shown in Table 1.

Table 1: Age Distribution among Suspected UTI Patients

\begin{tabular}{|l|l|l|}
\hline Age group & Frequency & Percentage \\
\hline $0-10$ & 26 & 6.5 \\
\hline $10-20$ & 52 & 13.0 \\
\hline $21-30$ & 111 & 27.7 \\
\hline $31-40$ & 55 & 13.8 \\
\hline $41-50$ & 42 & 10.5 \\
\hline $51-60$ & 46 & 11.5 \\
\hline $61-70$ & 34 & 8.5 \\
\hline $71-80$ & 22 & 5.5 \\
\hline$>80$ & 12 & 3.0 \\
\hline Total & 400 & 100 \\
\hline
\end{tabular}

\section{Bacterial Growth Representation}

Out of 400 urine samples of suspected patients, growth of multiple organism occurred in 27 samples $(6.75 \%)$, significant growth of a singular organism that causes UTI was found in 173 samples (43.25\%), in significant growth of microorganism occurred in 31 samples $(7.75 \%)$ and no growth of microorganism occurred in 169 samples (42.25\%) as shown in Figure 1.

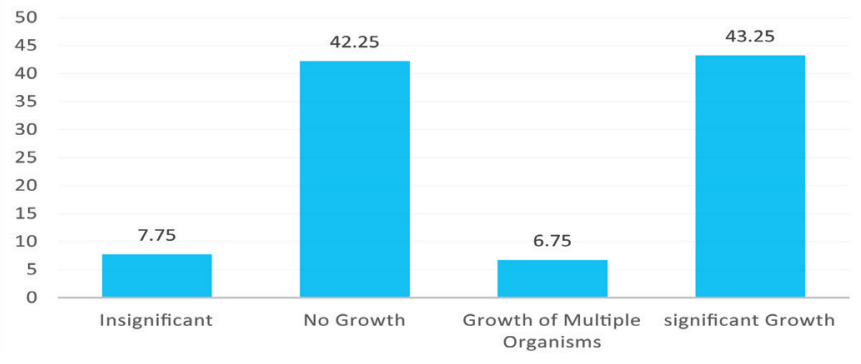

Figure 1 : Bacterial Growth in Urine Samples of Suspected Patients

\section{Different Isolated Organism}

Total nine species of microorganisms were isolated and among which, E. coli $(65.12 \%)$ was the most common pathogen causing UTI followed by Staphylococcus species (11.63\%), Proteus species (6.98\%), Klebsiella species (6.4\%), Enterococcus species $(5.81 \%)$, Citrobactor species (1.74\%), Aciretobacter species $(1.16 \%)$, Pseudomonas species $(0.58 \%)$ and Candida albicans $(0.58 \%)$ as shown in Figure 2.

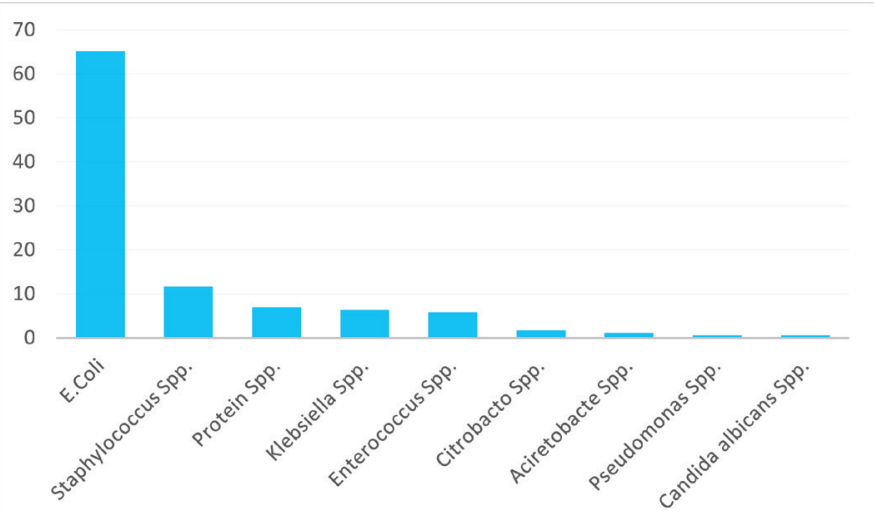

Figure 2: Percentage of Different Isolated Organisms

\section{Sensitivity Pattern of Antimicrobials}

Antimicrobial susceptibility test shows that Amikacin to be most sensitive antimicrobials among others with the sensitivity percentage of $94 \%$ and Ampicillin a least sensitive which shows sensitive in $25 \%$ of microorganism. The order of sensitivity pattern is Amikacin $>$ Nitrofurantoin $>$ Gentamicin $>$ Azithromicin $>$ Cefpodoxine $>$ Ceftriaxone $>$ Cefixime $>$ Ofloxacin $>$ Cotrimoxazole $>$ Ciprofloxacin $>$ Norfloxacin $>$ Ampicillin.

\section{Resistance Pattern of Antimicrobials}

Ampicillin was found to be highly resistant showing resistance in $75 \%$ of organisms and Amikacin least resistant $4.72 \%$. Resistance pattern of microorganism to different antibiotics is shown in Figure 3. Order for resistance pattern is Ampicillin $>$ Cephalexin $>$ Cotrimoxazole $>$ Norfloxain $>$ Cefixime $>$ Ceftriaxone $>$ Ciprofloxaxin $>$ Azithromicin $>$ Ofloxacin $>$ Gentamicin $>$ Nitrofurantoin $>$ Amikacin.

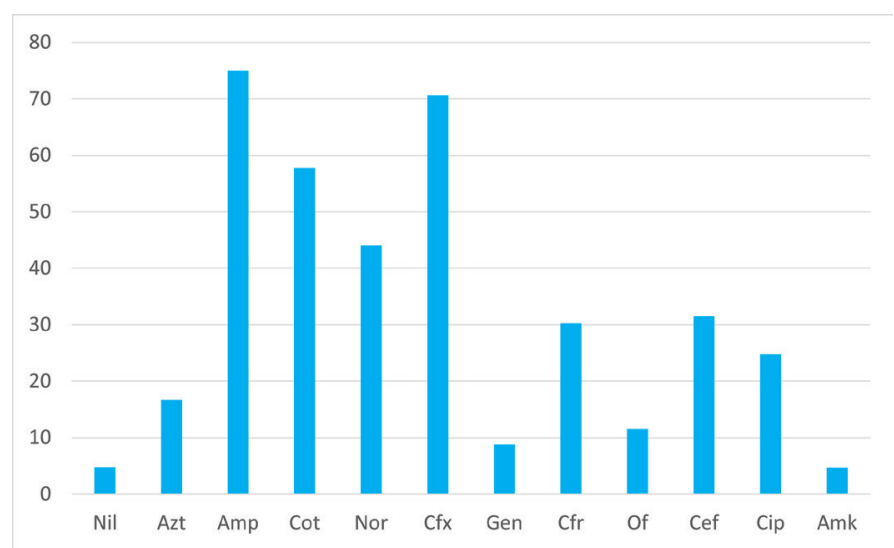

Figure 3: Resistance Pattern of Antibiotics 


\section{DISCUSSION}

The age group analysis shows that the female patients in the range of 20-30 years had highest prevalence rate $(27.8 \%)$ and then the least was found in age group more than 80, this might be due to reason that female in the reproductive age groups has a high prevalence rate of UTI and similarly the incidence of symptomatic UTI is high in sexually active young women. ${ }^{7}$ The uropathogens found in this study are similar to uropathogens identified in other studies conducted in different parts of the World. ${ }^{8}$ The similarities and differences in the type and distribution of uropathogens may result from different environmental conditions and host factors, and practices such as healthcare and education programmes, socioeconomic standards and hygiene practices in each country. ${ }^{9}$
Among different uropathogens, the most predominant organism was found to be E. coli $(65.1 \%)$, which is confirmatory to the study done by Oluremi, $2011^{10}$ and also in study conducted by Chakupurakal et al., 2010 where the predominant organism was E.coli. ${ }^{11}$ and in number of reports World Wide where the particular organisms is identified as most common uropathogens. ${ }^{12}$ The dominance of E. coli is followed by Staphylococcus aureus $(11.6 \%)$ in this study resembles to the study done by Jha and Bapat, 2005 which found out that Staphylococcus aureus (23\%) was the second most organisms causing UTI. ${ }^{13}$

Antibiotic susceptibility test reveals that higher percentage of susceptibility for Amikacin (94\%), followed by Nitrofurantoin (92.8\%), Gentamicn (88.55\%) and least for Ampicillin (25\%) as shown in Table 2.

Table 2: Sensitivity Pattern of Microorganism to Different Antibiotics.

\begin{tabular}{|c|c|c|c|c|c|c|c|c|c|c|c|c|}
\hline Antibiotics $\quad \rightarrow$ & Amk & Cip & Cef & Ofl & $\mathrm{Cfr}$ & Gen & Nor & $\mathbf{C f t}$ & Cot & Amp & Azt & Nit \\
\hline No of samples $\rightarrow$ & 148 & 97 & 54 & 78 & 86 & 114 & 59 & 24 & 45 & 48 & 54 & 126 \\
\hline Microorganism $\downarrow$ & $\mathrm{n}(\%)$ & $\mathrm{n}(\%)$ & $\mathrm{n}(\%)$ & $\mathrm{n}(\%)$ & $\mathrm{n}(\%)$ & $\mathrm{n}(\%)$ & $\mathrm{n}(\%)$ & $\mathrm{n}(\%)$ & $\mathrm{n}(\%)$ & $\mathrm{n}(\%)$ & $\mathrm{n}(\%)$ & $\mathrm{n}(\%)$ \\
\hline E. Coli & $92(62)$ & $43(44.3)$ & $19(35.18)$ & $29(37.2)$ & $35(40.7)$ & $75(65.78)$ & $12(20)$ & $13(54.16)$ & $13(28.9)$ & $7(15)$ & $34(63)$ & $87(69)$ \\
\hline Klebsiella Spp. & $9(6.1)$ & $4(4.12)$ & $4(7.4)$ & $2(2.56)$ & $3(3.48)$ & $4(3.5)$ & $2(3.4)$ & 0 & $2(4.44)$ & $1(2.1)$ & 1(1.9) & $6(4.76)$ \\
\hline Proteus Spp. & $11(7.4)$ & $5(5.15)$ & $3(5.55)$ & $3(3.84)$ & $4(4.65)$ & $7(6.14)$ & $2(3.4)$ & $1(4.16)$ & 0 & $1(2.1)$ & $3(5.6)$ & $10(7.93)$ \\
\hline Staphylococcus Spp & $17(11)$ & $3(3.09)$ & $5(9.25)$ & $9(11.5)$ & $5(5.81)$ & $8(7.01)$ & $8(14)$ & $2(8.33)$ & $6(13.3)$ & $1(2.1)$ & $5(9.3)$ & $4(3.17)$ \\
\hline Aciretobacte Spp. & $1(0.7)$ & 0 & 0 & 0 & 0 & 0 & 0 & 0 & 0 & 0 & 0 & $1(0.79)$ \\
\hline Enterococcus Spp. & $5(3.4)$ & 0 & 0 & 0 & 0 & $4(3.5)$ & $1(1.7)$ & 0 & $3(6.66)$ & $1(2.1)$ & 0 & $6(4.76)$ \\
\hline Candida albicans Spp. & $1(0.7)$ & 0 & 0 & 0 & 0 & 0 & 0 & 0 & 0 & 0 & 0 & 0 \\
\hline Pseudomonas Spp. & $1(0.7)$ & $1(1.03)$ & $1(1.85)$ & $1(1.28)$ & $3(3.48)$ & $1(0.87)$ & $1(1.7)$ & 0 & 0 & 0 & $1(1.9)$ & 0 \\
\hline Citrobactor Spp. & $2(1.4)$ & 0 & 0 & $2(2.56)$ & $1(1.16)$ & $2(1.75)$ & $1(1.7)$ & 0 & $2(4.44)$ & $1(2.1)$ & 0 & $3(2.38)$ \\
\hline Total & $139(94)$ & $56(57.7)$ & $32(59.23)$ & $46(58.9)$ & $51(59.3)$ & $101(88.55)$ & $27(46)$ & $16(66.65)$ & $26(57.8)$ & $12(25)$ & $44(81)$ & $117(92.8)$ \\
\hline
\end{tabular}

n: number of samples, Amk: Amikacin, Cip: Ciprofloxacin, Cef: Cefixime, Ofl: Ofloxacin, Cfr: Ceftriaxone, Gen: Gentamicin, Nor: Norfloxacin, Cft: Cefpodoxine, Cot: Cotrimoxazole, Amp: Ampicillin, Azt: Azithromicin, Nit: Nitrofurantoin

This study resembles to the study conducted by Farjnia et al 2009 where higher percentage of susceptibility was seen for Amikacin $(96.6 \%) .{ }^{8}$ Second to Amikacin is the Nitrofurantoin which is considered as an appropriate agent for first-line treatment of community acquired UTIs, it can be administered orally and is highly concentrated in urine; it may therefore be the most appropriate agent for empirical use in uncomplicated UTI. Aminoglycosides (amikacin, gentamicin, and netilmicin) have also shown a decreasing resistance trend against E. coli from the year 2007 to 2009. Aminoglycosides being injectables are used restrictively in the communitycare setting and hence have shown better sensitivity rates. ${ }^{14}$

Ampicillin was found to show the higher resistant rate followed by Cephalexin and Cotrimoxazole which resembles to the study conducted by Nerukar et al., 2012 which shows that isolates of most of the species exhibited a high rate of resistance to Ampicillin, Cotrimoxazole, Cefazolin, Norfloxacin and Nitrofurantoin. Resistance to antibiotics develops due to its frequent misuse. ${ }^{15}$ The regional variation of resistance to antibiotics may be explained in part by different antibiotic practices. The influence of excessive and inappropriate use on the development of antibiotic resistant strains particularly broad spectrum antibiotics prescribed empirically 
has been demonstrated. Transmission of resistant isolates between people and/or by consumption of foods originated from animals that have received antibiotics and greater mobility of individuals World wide has also contributed to the expansion of antibiotic resistance. ${ }^{8}$

\section{CONCLUSION}

Female patients in reproductive age groups are more prone to develop UTI. E. coli remains the most common pathogens in patients with UTI. The pattern of sensitivity of bacteria to antibiotics varies over time and in different geographical regions, antibiotic treatment of infections should be based on local experience of sensitivity and resistance pattern.

\section{REFERENCES}

1. Karki A, Tiwari BR, Pradhan SB. Study of Bacteria Isolated from Urinary Tract Infections and Their Sensitivity Pattern. J Nepal Med Assoc 2004; 43: 200-203.

2. Foxman B. Epidemiology of Urinary tract Infections; Incidence, Morbidity, Economic Costs. Dis Mon 2003; 49: 5370 .

3. Akortha EE, Ibadin OK. Incidence and Antibiotic Susceptibility Pattern of Staphylococcus aureus Amongst Patients with Urinary Tract Infection (UTI) in UBTH Benin City, Nigeria. Afr J Biotechnol 2008; 7: 1637-1640.

4. Hooton TM, Stamm WE. Infectious Disease Clinics of North America Department of Medicine, University of Washington School of Medicine, Seattle, USA, 1997; 11: 551581.

5. Ghimire P, Parajuli K. A Text Book of Meidcal Microbiology. 1st ed. Kathmandu, Vidyarthi Pustak Bhandar 2006; 89-158.

6. Wagnleher FME, Naber KG. Treatment of Bacterial Urinary Tract Infection; Presence and Future. Eur Urol 2005; 49: 235-244.

7. Dash M, Padhi S, Mohanty I, Panda P, Parida B. Antimicrobial Resistance in Pathogens Causing Urinary Tract Infections in a Rural Community of Odisha. India J Family Community Med 2013; 20: 20-26.

8. Farajnia S, Alikhani MY, Ghotaslou R, Naghili

B, Nakhlband A. Causative Agents and Antimicrobial
Susceptibilities of Urinary Tract Infections in the Northwest of Iran Safar. Int J Infect Dis 2009; 13: 140-144.

9. Amin M, Mehdinejad M, Pourdangchi Z. Study of Bacteria Isolated from Urinary Tract Infections and Determination of Their Susceptibility to Antibiotics. Jundishapur Journal of Microbiology 2009; 2: 118-123.

10. Oluremi BB, Idowu AO, Olaniyi JF. Antibiotic Susceptibility of Common Bacterial Pathogens in Urinary Tract Infections in a Teaching Hospital in Southwestern Nigeria. Afr J Microbiol Res 2011; 5: 3658-3663.

11. Chakupurakal R, Ahmed M, Sobithadevi DN, Chinnappan S, Reynolds T. Urinary Tract Pathogens and Resistance Pattern. J Clin Pathol 2010; 63: 652-654.

12. Baral P, Neupane S, Marasini BP, Ghimire KR, Lekhak B, Shrestha B. High Prevalence of Multi Drug Resistance in Bacterial Uropathogens From Kathmandu, Nepal. BMC Research Notes 2012; 5: 2-9.

13. Jha N, Bapat SK. A Study of Sensitivity and Resistance of Pathogenic Microorganism causing UTI in Kathmandu valley. Kathmandu Univ Med J 2005; 3: 123-129.

14. Sood S, Gupta R. Antibiotic Resistance Pattern of Community Acquired Uropathogens at a Tertiary Care Hospital in Jaipur, Rajasthan. Indian J Community Med 2012; 37: 39-44. 15. Nerurkar A, Solanky P, Naik SS. Bacterial Pathogens in Urinary Tract Infection and Antibiotic Susceptibility Pattern. J Pharm Biomed Sci 2012; 21: 1-3. 